www.jmscr.igmpublication.org

Impact Factor (SJIF): 6.379

Index Copernicus Value: 71.58

ISSN (e)-2347-176x ISSN (p) 2455-0450

crossref DOI: _https://dx.doi.org/10.18535/jmscr/v6i2.34

Journal Of Medical Science And Clinical Research

\title{
Acute Intermittent Porphyria Presenting as SIADH: A Rare Presentation
}

\author{
Authors \\ Rupinder Kaur ${ }^{1}$, Jagminder Singh ${ }^{2}$, Simran Kaur ${ }^{3}$, Harmandeep Singh Chahal', \\ Rajesh Mahajan ${ }^{5}$ \\ ${ }^{1}$ Assistant Professor, Dept of Emergency Medicine, Dayanand Medical College and Hospital, Ludhiana, \\ Punjab, India \\ ${ }^{2}$ Senior Resident, Dept of Neurosurgery, Dayanand Medical College and Hospital, Ludhiana, Punjab, India \\ ${ }^{3}$ Assistant Professor, Dept of Nephrology, Dayanand Medical College and Hospital, Ludhiana, Punjab, India \\ ${ }^{4}$ Assistant Professor, Dept of Urology, Dayanand Medical College and Hospital, Ludhiana, Punjab, India \\ ${ }^{5}$ Professor, Department of Medicine, Dayanand Medical College and Hospital, Ludhiana, Punjab, India \\ Corresponding Author
}

\section{Simran Kaur}

Assistant Professor, Dept of Nephrology, Dayanand Medical College and Hospital, Ludhiana, Punjab, India

Abstract
Acute intermittent porphyria (AIP) is an autosomal dominant metabolic disorder caused by deficiency of
porphobilinogen deaminase; an enzyme involved in synthesis of heme. We reported a case of 20 year old
female patient presented with abdominal pain, vomiting, seizures and altered sensorium. She was
diagnosed as a case of AIP in porphyric crisis with hyponatremia due to syndrome of inappropriate anti-
diuretic hormone secretion (SIADH) and was managed with dextrose, hypertonic saline and other
supportive measures. Early diagnosis and treatment increases chances of better outcome.

\section{Introduction}

Acute intermittent porphyria is an autosomal dominant hepatic porphyria, resulting from deficiency of an enzyme, porphobilinogen deaminase. This enzyme is involved in the heme synthesis pathway. This is the second most common porphyria with an estimated prevalence of approximately 5 per 100,000 people. ${ }^{[1]}$ In AIP, the porphyrin precursors, porphobilinogen and amino-levulinic acid (ALA), accumulate. The patient may present with abdominal pain or with neuropsychiatric manifestations. Diagnosis is confirmed with urine (PBG) porphobilinogen test. ${ }^{[2]}$ Treatment involves removal of precipitating factor, administration of heme arginate, dextrose and symptomatic treatment. Delay in diagnosis and thus treatment can result in increased morbidity and mortality. We reported a case of acute intermittent porphyria presented as syndrome of inappropriate anti-diuretic hormone secretion (SIADH).

\section{Case History}

A 20 year old female patient presented to emergency with history of pain abdomen which was severe and colicky associated with nausea and vomiting. It was followed by history of seizure and altered sensorium. Patient got admitted to a 
local hospital for intractable abdominal pain but with no relief, from where she was referred to another hospital, where she developed seizures followed by altered sensorium. As her general condition deteriorated, patient was referred to our hospital emergency. The mother of patient also gave history of long journey and low calorie intake prior to illness. There was also history of fever one day prior to the development of abdominal pain. There was no history of similar complaints in the past or in the family. On examination, patient was in altered sensorium. She was afebrile. Her blood pressure was 100/60 $\mathrm{mmHg}$, pulse rate was $98 / \mathrm{min}$, respiratory rate was 22/min. On central nervous system examination, signs of meningeal irritation were absent, pupils were normal size reacting to light, both plantars were flexor and all reflexes were normal. Abdomen examination revealed absence of any tenderness, rigidity and presence of normal bowel sounds. Chest examination and cardiovascular examination was within normal limits. Initial investigations showed haemoglobin $11.8 \mathrm{~g} / \mathrm{dl}$, white blood cell count $14.1 / \mathrm{mm} 3$ with normal differential counts, platelet count 267lac/mm3, blood urea-19 mg/dl, serum creatinine-0.56 mg/dl, serum sodium $-107 \mathrm{meq} / \mathrm{l}$, serum potassium-3.68meq/1, serum calcium$9.0 \mathrm{mg} / \mathrm{dl}$, serum magnesium- $1.70 \mathrm{mg} / \mathrm{dl}$, serum phosphorus-3.14 mg/dl, serum amylase-48 U/l, serum lipase-14 U/l. Urine routine examination was normal. Serum osmolality was 272 mosmol/kg and urine osmolality was 193 mosmol $/ \mathrm{kg}$. Urinary electrolytes showed sodium $24 \mathrm{mmol} / \mathrm{l}$, potassium $3.43 \mathrm{mmol} / \mathrm{l}$, chloride $15 \mathrm{mmol} / \mathrm{l}$. Thyroid profile, rheumatoid factor, antinuclear antibody, serum cortisol levels and lead levels were normal. X-ray chest, X-ray abdomen as well as ultrasound abdomen revealed no abnormality.MRI brain and cerebrospinal fluid examination was done, reported normal. On the basis of symptoms of patient, dark coloured urine and hyponatremia, possibility of acute intermittent porphyria (AIP) was kept and patient's urine sample was sent for porphobilinogen (PBG) test.
Urine for PBG came out to be positive which confirmed the diagnosis of AIP. Serum lead levels were normal. The final diagnosis of the patient was acute intermittent porphyria in porphyric crisis with severe hyponatremia, SIADH. Patient was managed with dextrose infusion; hyponatremia was corrected by giving hypertonic saline and tolvaptan; gabapentin was given for seizures and narcotics were given for abdominal pain. Heme infusion was not given because of non-availability. Patient's sensorium improved and she started accepting orally. She was encouraged to have carbohydrate rich diet. She recovered fully without any neurological deficit and was discharged after 12 days. The patient and her parents were counselled about the disease and the precipitating factors and list of restricted medicines was given to them.

\section{Discussion}

Acute intermittent porphyria is a metabolic disorder with autosomal dominant inheritance with incomplete penetrance and it predominantly affects young females after puberty. ${ }^{[3,4]}$ Acute intermittent porphyria usually presents with neuro-visceral and psychiatric manifestations like abdominal pain, vomiting, obstipation, confusion, disorientation and hallucinations. In acute crisis of porphyria, patient may have encephalopathy ranging from confusion to frank psychosis associated with metabolic derangements of syndrome of inappropriate anti diuretic hormone secretion. ${ }^{[5]}$ Patient can develop seizures and even coma due to neurological effects and hyponatremia. ${ }^{[6]}$ In our case, the patient was 20 year old female and she presented to emergency with history of severe abdominal pain and vomiting which was followed by seizures and altered sensorium. Acute attacks of porphyria may be precipitated by various factors such as alcohol, dietary restrictions, infection, fever, stress, endogeneous sex hormones or drugs. ${ }^{[7]}$ In our case, patient had history of fever one day prior to development of abdominal pain and history of stress which may be the precipitating factor for 
acute attack of porphyria. There is a very characteristic discordance between the severity of the patient's complaints and the objective clinical findings. ${ }^{[8]}$ In our case, patient was having history of severe abdominal pain for which she was admitted in two different hospitals prior to admission in our hospital but without any finding in physical examination and other routine investigations. In patients with AIP, investigations like complete blood count, renal and liver function test, routine examination of urine are usually normal. In upto $20 \%$ of patients with acute porphyric crisis, hyponatremia is observed due to SIADH, but diagnosis requires a high index of suspicion. Diagnosis can be established with characteristic history, reddish brown colour of urine on physical examination, urine positive for porphobilinogen (PBG) and decreased activity of PBG deaminase activity in red blood cells. ${ }^{[2]}$ DNA testing can help in detecting the underlying mutation. In our case, patient was having low serum sodium level i.e $107 \mathrm{meq} / \mathrm{l}$, due to SIADH which was responsible for the seizures and features of encephalopathy in the patient. Colour of the urine was dark brown and urine for PBG was positive which confirmed the diagnosis of acute intermittent porphyria in the patient. Neuroimaging revealed no abnormality. The important differential diagnosis of AIP includes acute abdomen, lead poisoning and psychosis. Removal of precipitating factor and supportive treatment are of utmost importance. ${ }^{[2]}$ Administration of heme arginate and dextrose are the mainstay of treatment. We managed our patient with dextrose and other supportive measures. Hyponatremia was corrected with $3 \%$ hypertonic saline and patient was started on tolvaptan. Patient recovered without any neurological deficit.

Education and counselling of the patient is important. Patient should be informed about the various triggers of the porphyric crisis and the drugs that should be avoided.

\section{Conclusion}

A high index of suspicion is required in hyponatremic patients for the diagnosis of Acute intermittent porphyria (due to associated SIADH), especially in diagnostic dilemma arising due to associated profuse vomiting. Early diagnosis and treatment may significantly reduce the morbidity and mortality.

\section{Consent}

Written informed consent was obtained from the patient for publication of this case report and accompanying images.

\section{Conflict of Interest: None}

\section{References}

1. Ramanujam VM, Anderson KE. Porphyria Diagnostics-Part 1: A Brief Overview of the Porphyrias. Curr Protoc Hum Genet. 2015 Jul 1. 86:17.20.1-17.20.26.

2. Anderson KE, Bloomer JR, Bonkovsky HL, Kushner JP, Pierach CA, Pimstone NR et al. Recommendations for the diagnosis and treatment of the acute porphyrias. Ann Intern Med. 2005; 142: 439-50.

3. Anderson KE, Sassa S, Bishop DF, Desnick RJ. Disorders of heme biosynthesis: $\mathrm{X}$-linked side roblastic anemia and the porphyrias. In Scriver CR, Beaudet A, Sly WS, Valle D (Eds). The metabolic and molecular basis of inherited disease.8th Edition. New York: “A21McGraw Hill, 2001:2991-3062.

4. Andersson $\mathrm{C}$, Innala $\mathrm{E}$, Backstrom $\mathrm{T}$. Acute intermittent porphyria in women: Clinical expression, use and experience of exogenous sex hormones - a population based study in Sweeden. J Intern Med. 2003; 254: 176-83.

5. Oomman A, Gurtoo A. Acute intermittent porphyria as a cause of respiratory failure. J Indian Med Assoc 2002;100:44-6. 
6. Periasamy V, al Shubaili A, Girsh Y. Diagnostic dilemmas in acute intermittent porphyria. A case report. Med Princ Pract 2002;11:108-11.

7. Kochar SK, Mahajan M, Gupta RP. Acute attacks of AIP (acute intermittent porphyria) with severe vivax malaria associated with convulsions: a case report. J Vector Borne Dis 2009;46: 307-09.

8. Tasnadi G, Bor M, Pusztai A, Szekely E. Acute porphyrias in differential diagnosis. Orv Hetil. 2003 Apr 27. 144(17):811-18. 